\title{
Changes in carbohydrate metabolism of testicular germ cells during meiosis in the rat
}

\author{
Malini Bajpai, Gopal Gupta and B S Setty \\ Division of Endocrinology, Central Drug Research Institute, Lucknow 226001, India \\ (Correspondence should be addressed to G Gupta)
}

\begin{abstract}
A study was undertaken to estimate the activities of the key enzymes of glycolysis, the pentose phosphate pathway and the tricarboxylic acid (TCA) cycle in purified rat spermatocytes and spermatids, which have been shown to die in glucose-containing medium and require lactate/pyruvate for maintaining normal ATP concentrations. The aim was to elucidate the changes in the glycolytic and oxidative potential of germ cells undergoing meiosis. Pachytene spermatocytes and round spermatids from adult rat testis were purified to $\sim 90 \%$ purity by trypsin digestion followed by a combination of centrifugal elutriation and Percoll density gradient centrifugation. After the purity and viability of these cells had been established, their contents of hexokinase, phosphofructokinase, lactate dehydrogenase (LDH) and LDH-X of glycolysis, glucose 6-phosphate dehydrogenase of the pentose phosphate pathway and citrate synthase, aconitase, malate dehydrogenase and 2-oxoglutarate dehydrogenase of the TCA cycle were estimated. These enzymes were also estimated in epididymal spermatozoa for comparison with the testicular germ cells. The results indicate greater activity of glycolytic and pentose phosphate pathway enzymes in spermatocytes than in spermatids, which exhibited greater activity of TCA cycle enzymes than the former. The difference in activity was statistically significant for most of the enzymes studied. In contrast, spermatozoa exhibited markedly greater activity of glycolytic enzymes and significantly lower activity of pentose phosphate pathway and TCA cycle enzymes than did the testicular germ cells. We conclude that the unusual dependence of spermatids exclusively on lactate may be due to their lower glycolytic potential, whereas spermatocytes with comparatively greater glycolytic activity have an intermediate dependence on lactate and are therefore able to utilise lactate, pyruvate, or both, while retaining a better ability to utilise glucose. Spermatozoa with the greatest glycolytic potential and the lowest TCA cycle activity appear to be 'programmed' to utilise exclusively glucose/fructose for energy.
\end{abstract}

European Journal of Endocrinology 138 322-327

\section{Introduction}

Spermatogenesis is a highly synchronised, regular, continuous and extremely complex process of cellular differentiation by which a spermatogonial 'stem cell' is gradually transformed into a highly specialised haploid spermatozoon. The halving of the number of chromosomes in the process of spermatogenesis provides an interesting model for the investigation of a developmental process involving structural and metabolic changes in the germ cells. It is well known that the spermatogonia may utilise glucose as the major energy substrate (1), but spermatocytes and spermatids suffer a rapid decline in their ATP content in glucosesupplemented media and require lactate/pyruvate for the maintenance of their ATP concentrations $(2,3)$. In contrast, spermatozoa use glucose/fructose as the major source of energy (4). Therefore, it appears that, at each stage of spermatogenesis, there is a change in the substrate required for energy. However, to date no study has thoroughly investigated the activities of the enzyme components of all the major metabolic pathways of energy metabolism of each germ cell type in the testis. The complexity of spermatogenesis has tended to discourage biochemical analysis of this process. The heterogeneous cell population of the testis makes the investigation of a single cell type difficult, and studies on whole testis preparations do not permit conclusions as to the enzyme content of specific populations of germ cells. Histochemical analysis has helped in the localisation of enzymes to specific cell types; however, for quantitative analysis it would be ideal to obtain homogeneous cell populations from testis (5). With the introduction of more modern techniques of cell purification, namely unit gravity sedimentation and centrifugal elutriation $(6,7)$, it is now possible to isolate and purify specific germ cell populations to near homogeneity for studies on their metabolism.

In the present study, we isolated and purified primary spermatocytes (meiotic germ cells) and round 
spermatids (post-meiotic germ cells) from the testis of young adult rats to $\sim 90 \%$ purity and estimated the activities of some key enzymes of glycolysis, the pentose phosphate pathway and the tricarboxylic acid (TCA) cycle in these cells, to investigate the changes that occur in the genetic expression of metabolic enzymes during the process of meiosis. In some earlier studies $(1,8,9)$ the activities of glycolytic enzymes were estimated in enriched fractions of spermatocytes and spermatids; however, similar information is lacking on the enzymes of the TCA cycle, which apparently becomes more important during meiosis. Moreover, in the earlier studies, the activities were always expressed on the basis of the number of cells. Given that the spermatids are the result of two cell divisions and thus would have a smaller complement of cellular organelles (including mitochondria), expression of enzyme activities on the basis of cell numbers is not justified; specific enzyme activities per milligram of cell protein would give more meaningful data. We have therefore expressed all enzyme activities as specific activities. Epididymal spermatozoa (typical glucose-metabolising cells) have also been included in the study, as a reference for comparison with the testicular germ cell types. In addition, we have used centrifugal elutriation for purification of testicular germ cell types; not only is this a rapid method, but in addition the cells remain in isotonic medium during separation and are not exposed to the hypotonic and hypertonic solutions of a gradient.

\section{Materials and methods}

\section{Animals}

Young adult Sprague-Dawley rats weighing 180$200 \mathrm{~g}$ were obtained from the Institue colony. The animals were maintained in air-conditioned quarters $\left(25 \pm 2{ }^{\circ} \mathrm{C}\right)$ and fed with standard pellet diet. Water was available ad libitum.

\section{Chemicals}

All the chemicals used were obtained from Sigma Chemical Company, St Louis, MO, USA. All solutions were prepared in triple glass distilled water.

\section{Purification of germ cells}

Mid-pachytene spermatocytes and round spermatids were isolated by trypsin digestion and purified by centrifugal elutriation and density gradient centrifugation by the method of Meistrich et al. (7). Briefly, testes obtained from young adult animals were decapsulated, chopped and placed in Basal Medium Eagle (BME) containing trypsin $(0.2 \%)$, glucose $(0.1 \%)$ and DNase $(17 \mu \mathrm{g} / \mathrm{ml})$ at $34^{\circ} \mathrm{C}$ for $40 \mathrm{~min}$ with shaking in a shaker water bath. Trypsin action was stopped with soybean trypsin inhibitor $(0.04 \%)$ in the presence of DNase
( $2 \mu \mathrm{g} / \mathrm{ml}$ ) and the sample was filtered through 100 mesh screen and glass wool and placed in FCS (8\%) and DNase $(2 \mu \mathrm{g} / \mathrm{ml})$ in BME. The cells were later pelleted, suspended in BME (with DNase $2 \mu \mathrm{g} / \mathrm{ml}$ ) and loaded into a Beckman Elutriator Rotor (JE-6B) with a standard chamber fitted on a Beckman High Speed Centrifuge (J2-21). Two fractions (I and II) were collected at 3000 r.p.m. at flow rates of 18.0 and $31.5 \mathrm{ml} / \mathrm{min}$, and then the rotor speed was reduced to 2000 r.p.m. and another two fractions (III and IV) were collected at flow rates of 23.0 and $40.0 \mathrm{ml} / \mathrm{min}$ respectively. Fractions II and IV contained pachytene spermatocytes and round spermatids at purities of $\sim 80 \%$ and $75 \%$ respectively. The two fractions were layered separately over linear gradients of $25-37 \%$ and $23-33 \%$ Percoll respectively and centrifuged at $11000 \mathrm{~g}$ for $15 \mathrm{~min}$ in a Beckman swinging bucket (SW-41 Ti) rotor fitted on to a Beckman L8-M ultracentrifuge using slow acceleration and deceleration. The major band was recovered through a puncture in the side of the tube and diluted with BME. The cells were pelleted, suspended in BME and counted. After cell viability had been established by the trypan blue exclusion test, the cells were stored at $-20^{\circ} \mathrm{C}$ and the enzyme assays were completed the next day.

\section{Purity check \\ By cell morphology}

A thin smear of purified cells was air-dried and fixed with Bouin's fluid. The cells were later stained with haematoxylin and examined under a microscope. Percent contamination by other cell types was determined.

\section{By cell size}

The purity of cell type was also examined by a Coulter Cell Counter (Model ZM) with Channelyzer II as described by Bucci et al. (6).

\section{Isolation of spermatozoa}

Spermatozoa were isolated from cauda epididymis by giving it one or two cuts with fine scissors and gently teasing the tissue in BME. The spermatozoa were pelleted at $1000 \mathrm{~g}$ for $10 \mathrm{~min}$, washed and suspended in fresh BME. Purity was checked by cell mophology and viability by dye exclusion, as detailed earlier.

\section{Enzyme assays}

For all enzyme assays, the cells were thawed and homogenised at $4.0^{\circ} \mathrm{C}$ in an ice bath using Ultra Turrax (Janke \& Kunkel, Staufen, Germany). The homogenising medium for glycolytic enzymes was $50 \mathrm{mmol} / \mathrm{l}$ triethanolamine buffer ( $\mathrm{pH} 7.6$ ) containing $1 \mathrm{mmol} / \mathrm{l}$ EDTA, $2 \mathrm{mmol} / \mathrm{l} \mathrm{MgCl}_{2}$ and $30 \mathrm{mmol} / \mathrm{l}$ mercaptoethanol. The homogenate was centrifuged at $4^{\circ} \mathrm{C}$ for $30 \mathrm{~min}$ at 
$105000 \mathrm{~g}$ and the supernatant was used for enzyme estimations. For TCA cycle enzymes, cells were homogenised in $0.1 \mathrm{~mol} / \mathrm{l}$ potassium phosphate buffer $(\mathrm{pH}$ 8.0) containing $10 \mathrm{mmol} / \mathrm{l}$ EDTA, $0.1 \%$ sodium deoxycholate and $1 \%$ BSA. A supernatant obtained at 10000 r.p.m. $\times 10 \mathrm{~min}$ was used for enzyme assays. The assay procedures followed have been detailed earlier $(10,11)$. All enzyme assays were performed in duplicate and the mean of the two was considered as one value; results are expressed as mean \pm S.E. of five such values. A unit of enzyme activity was defined as $1 \mu \mathrm{mol}$ substrate transformed $/ \mathrm{min}$ at $30^{\circ} \mathrm{C}$. Results were analysed by Student's $t$-test and $P$ values $<0.05$ were considered to be significant.

\section{Results}

Trypsinisation of testicular tissue resulted in complete separation of testis cells (Fig. 1a); after elutriation, these were isolated into a spermatocyte $(\sim 80 \%$ mid-pachytene) fraction and a spermatid ( $\sim 75 \%$ round spermatid $)$ fraction. Density gradient centrifugation of spermatocyte and spermatid fractions gave $>90 \%$ purity of the two cell types (Fig. $1 b$ and $c$ ). The trypan blue exclusion test showed $>95 \%$ viability of the purified cells in the two fractions. Isolated spermatozoa exhibited $>95 \%$ purity and viability.

Figure 2 shows the activities of key enzymes of glycolysis (hexokinase, phosphofructokinase, lactate dehydrogenase (LDH) and $\mathrm{LDH}-\mathrm{X})$, the pentose phosphate pathway (glucose 6-phosphate dehydrogenase) and the TCA cycle (malate dehydrogenase, 2-oxoglutarate dehydrogenase, citrate synthase and aconitase), expressed as units/mg protein in purified spermatocytes, spermatids and spermatozoa of rat. Measurable activities of all these key enzymes were detected in spermatocytes, spermatids and spermatozoa, with significant differences between values in the different cell types.

\section{Glycolysis}

The enzymes of the glycolytic pathway exhibited significantly greater activities in spermatocytes than in spermatids; the differences between their hexokinase, phosphofructokinase, $\mathrm{LDH}$ and $\mathrm{LDH}-\mathrm{X}$ activities and those in spermatids were statistically significant $(P<0.05,0.01,0.05$ and 0.05 respectively). Spermatozoa exhibited the greatest glycolytic activity; the difference between their hexokinase, phosphofructokinase, $\mathrm{LDH}$ and LDH-X activities and those of spermatids were statistically significant $(P<0.001,0.001,0.01$ and 0.001 respectively). Phosphofructokinase showed the lowest activity, and LDH the highest (Fig. 2).

\section{Pentose phosphate pathway}

As in the case of the enzymes of glycolysis, the enzymes of the pentose phosphate pathway also showed
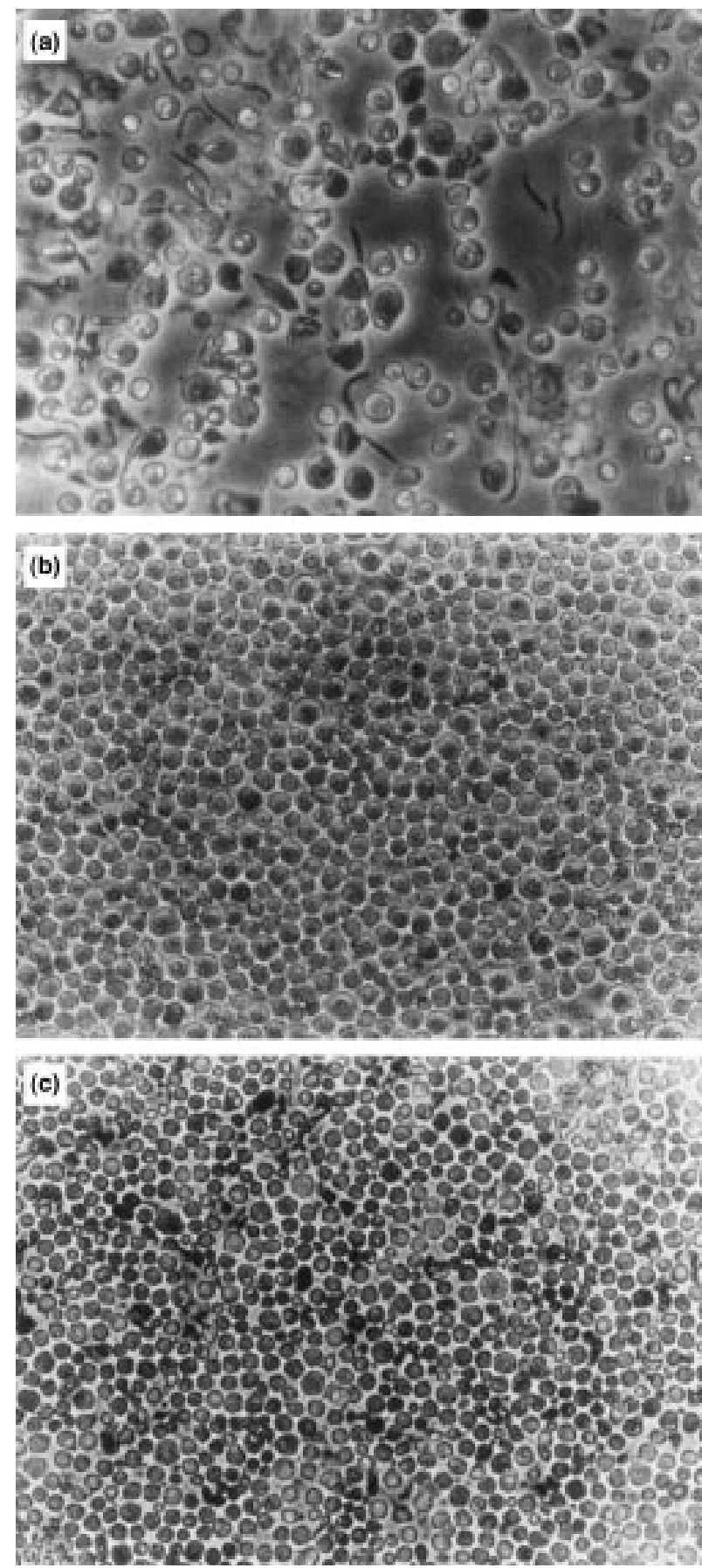

Figure 1 (a) Unseparated cells; (b) 90\% pure pachytene spermatocytes; $(c) \sim 90 \%$ pure round spermatids. Original magnification: $\times 600$.

significantly greater activity in spermatocytes than in spermatids. The enzyme glucose 6-phosphate dehydrogenase showed $\sim 20 \%$ greater activity in spermatocytes and the difference from that in spermatids was statistically significant $(P<0.05)$; the activity was 


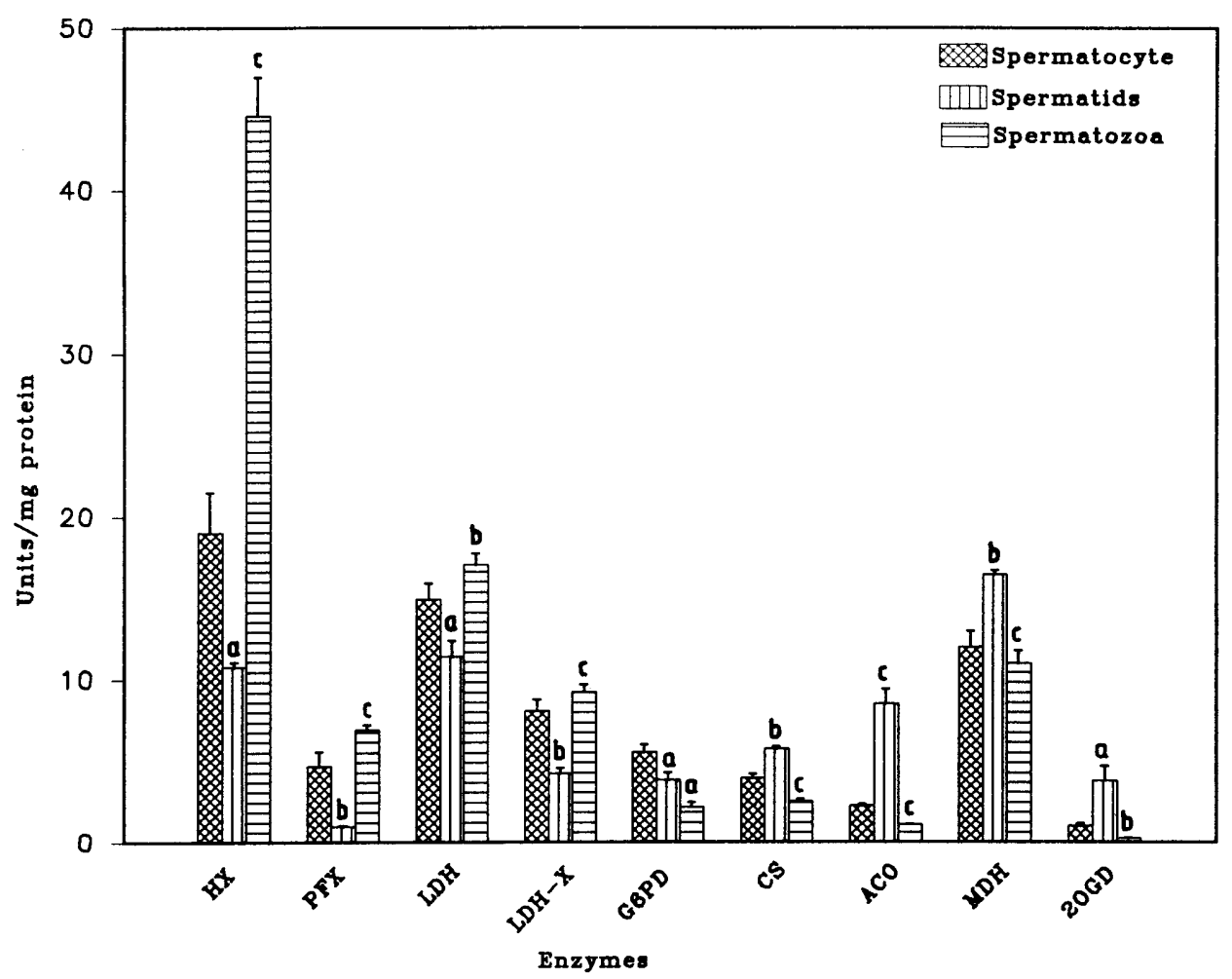

Figure 2 Specific activities (mean \pm S.E. of five values) of carbohydrate metabolising enzymes in purified spermatocytes, spermatids and spermatozoa. HX, hexokinase; PFX, phosphofructokinase; LDH, lactate dehydrogenase; LDH-X, lactate dehydrogenase-X; G6PD, glucose 6-phosphate dehydrogenase; CS, citrate synthase; ACO, aconitase; $\mathrm{MDH}$, malate dehydrogenase; 2OGD, 2-oxoglutarate dehydrogenase. ${ }^{\mathrm{a}} P<0.05 ;{ }^{\mathrm{b}} P<0.01 ;{ }^{\mathrm{c}} P<0.001$ ( $P$ values are for comparisons of spermatids with spermatocytes, and spermatozoa with spermatids).

further significantly reduced in spermatozoa $(P<0.05)$ compared with spermatids (Fig. 2).

\section{TCA cycle}

The enzymes of TCA cycle exhibited lower activities in spermatocytes than in spermatids. Malate dehydrogenase, 2-oxoglutarate dehydrogenase, citrate synthase and aconitase showed greater activities in spermatids and the differences from the activities in spermatocytes were statistically significant $(P<0.01,0.05,0.01$ and 0.01 respectively). Spermatozoa exhibited the lowest TCA cycle activity and, compared with activities in spermatids, significantly lower activities of citrate synthase $(P<0.001)$, aconitase $(P<0.001)$, malate dedydrogenase $(P<0.001)$ and 2 -oxoglutarate dehydrogenase $(P<0.01)$ were detectable in spermatozoa. Malate dehydrogenase showed the greatest activity, and 2-oxoglutarate dehydrogenase showed the lowest (Fig. 2).

\section{Discussion}

The activities of key enzymes of the major metabolic pathways of carbohydrate metabolism give a clear indication that germ cells undergoing meiosis exhibit a change in the type of substrate required for their energy metabolism. The equilibrium between glycolysis and the TCA cycle shifts more in favour of oxidative metabolism in post-meiotic germ cells. Thus the ratio of glycolysis to TCA cycle activity is likely to be greater in spermatocytes than in spermatids. However, in spermatozoa the equilibrium again shifts drastically in favour of glycolysis.

Nakamura et al. (9) previously measured the activities of glycolytic enzymes in enriched fractions of rat spermatocytes and spermatids, and showed markedly lower activities in spermatids than in spermatocytes. We also found significantly lower activities of glycolytic enzymes in spermatids than in spermatocytes. However, the vast difference in activities between the two cell types reported earlier $(8,9)$ was due to the basis on which the investigators had expressed the enzyme activities namely that of cell numbers. As explained in the introduction, a more accurate measure of the reduction in glycolytic potential during meiosis can be obtained by expressing activities on the basis of milligrams of cell protein, rather than cell number. However, our values can be converted approximately into units $/ 10^{6}$ cells by dividing by a factor of 9.7 for spermatocytes, 12.5 for spermatids and 8.8 for spermatozoa. 
The lack of earlier information on the activities of TCA cycle enzymes in spermatocytes and spermatids is surprising, as the involvement of this pathway in the production of ATP by the two cell types has always been considered to be very important $(3,12$, 13). In the present study, our finding of a significant increase in TCA cycle enzyme activities in postmeiotic germ cells (spermatids) compared with those in spermatocytes clearly indicates a preference for the TCA cycle over glycolysis in spermatids. This observation is supported by the earlier finding that respiratory inhibitors reduce pyruvate/lactate consumption by spermatocytes, whereas spermatids degenerate completely in their presence (13).

Both spermatocytes and spermatids have been shown to suffer a rapid decline in their ATP concentrations in glucose-supplemented media (14-16) and, whereas lactate alone was able to restore the ATP concentrations of spermatids (16), lactate and pyruvate were equipotent in maintaining normal ATP concentrations of spermatocytes (1). Isolated rat spermatocytes, however, survived for at least $24 \mathrm{~h}$ in the presence of glucose (17). If this is the case, then the spermatocytes are half-way towards becoming dependent on lactate. Thus spermatocytes retain a better ability to oxidise glucose, as is indicated by their higher activities of glycolytic enzymes compared with spermatids.

The germ cells have some pentose phosphate pathway activity, as indicated by glucose 6-phosphate dehydrogenase activity. As it is a cytosolic enzyme, glucose 6-phosphate was naturally found to have a greater activity in spermatocytes. This pathway is required to meet the needs of biosynthesis of nucleotides for RNA by generating important substrates such as $\mathrm{NADPH}$ and ribose 5-phosphate. Very little is known about the synthesis of nucleotides and purine salvage reactions in spermatogenic cells (18).

Germ cells in mammalian testis develop in a tubular environment that is controlled to a high degree by Sertoli cells. The fluid of the seminiferous tubules has been found to be rich in lactate and very poor in glucose and pyruvate $(19,20)$. Thus spermatocytes with sufficient potential to utilise glucose and pyruvate may actually be utilising mostly lactate as the substrate available in bulk in situ. Isolated germ cells, however, consume oxygen at the maximum rate in the presence of both lactate and glucose (2). In contrast, critical dependence of round spermatids on the TCA cycle and electron transport system for energy is indicated by the inhibition of their ATP synthesis with lactate as substrate in response to the addition of inhibitors of alpha-keto acid dehydrogenase or retinol, rutamycin, 2,4-dinitrophenol etc. (3). Lactate also stimulated RNA and protein synthesis in spermatids (2). Early studies by Free (21) had shown that carbohydrates are an exceedingly important energy source for mammalian testis. Sertoli cells incubated in glucose-containing medium under aerobic conditions convert glucose to lactate $(22,23)$, which is secreted into the medium. The lactate secreted by the Sertoli cells is stimulated by follicle-stimulating hormone $(24,25)$ and is directed towards the adluminal compartment. It is very likely that the rate of glycolysis and lactate production in situ is under fine regulation to maintain a steady-state concentration of lactate in the spermatogenic microenvironment (26). Thus the survival of the advanced germ cells in testis is strictly dependent on carbohydrate metabolism, including both anaerobic (glycolysis) and aerobic (TCA cycle) pathways. The sugars are actively glycolysed by the Sertoli cells, which secrete lactate as the major energy substrate for spermatocytes and spermatids.

The germ cells use the TCA cycle preferentially over glycolysis; however, all the testicular germ cells do not rely on oxidative metabolism: spermatogonia may depend more on glycolysis, spermatocytes are intermediate and can depend to some extent on glycolysis, whereas spermatids use the TCA cycle exclusively for their energy. However, interestingly, spermatozoa again regain the ability to utilize glucose/fructose (27). Therefore, during spermatogenesis, the dependence of germ cells on lactate/pyruvate and glucose for energy metabolism keeps changing, but the advantage of this process remains an enigma.

\section{Acknowledgements}

The authors are thankful to Dr C M Gupta, Director and Dr V P Kamboj, former Director, for their interest in this study, which was supported by a grant from the Ministry of Health and Family Welfare, Government of India. The authors gratefully acknowledge the assistance provided by Mr JP Maikhuri.

CDRI Communication No.: 5715.

\section{References}

1 Nakamura M, Okinaga S \& Arai K. Metabolism of pachytene primary spermatocytes from rat testes: pyruvate maintenance of adenosine triphosphate level. Biology of Reproduction 198430 1187-1197.

2 Jutte NHPM, Grootegoed JA, Rommerts FFG \& Vander Molen HJ. Exogenous lactate is essential for metabolic activities in isolated rat spermatocytes and spermatids. Journal of Reproduction and Fertility 198162 399-405.

3 Mita M \& Hall PF. Metabolism of round spermatids from rats: lactate as the preferred substrate. Biology of Reproduction 198226 445-455.

4 Mann T. Metabolism of semen: fructolysis, respiration and sperm energetics. In Biochemistry of Semen and of Male Reproductive Tract, pp 265-307. London: Methuen, 1964.

5 Fritz IB. Selected topics on the biochemistry of spermatogenesis. In Current Topics in Cellular Regulation, vol 7, pp 129-174. Eds BL Horecker \& ER Stadtman. New York: Academic Press, 1973.

6 Bucci LR, Brock WA, Johnson TS \& Meistrich ML. Isolation and biochemical studies of enriched populations of spermatogonia and early primary spermatocytes from rat testes. Biology of Reproduction 198634 195-206. 
7 Meistrich ML, Longtin J, Brock WA, Grimes SR \& Macc ML. Purification of rat spermatogenic cells and preliminary biochemical analysis of these cells. Biology of Reproduction 198125 10651077.

8 Tvermyr SM, Froysa A, Jutte NHPM \& Hansson V. Glucose metabolism in rat germ cells: mechanism of action of gossypol. Annals of the New York Academy of Sciences 1984438 543-545.

9 Nakamura M, Fujiwara A, Yasumasu I, Okinaga S \& Arai K. Regulation of glucose metabolism by adenine nucleotides in round spermatids from rat testis. Journal of Biological Chemistry $198225713945-13950$

10 Gupta G, Srivastava A \& Setty BS. Androgenic regulation of glycolytic pathway in epididymis and vas-deferens of Rhesus monkey. Indian Journal of Experimental Biology 199331 305-311.

11 Gupta G, Srivastava A \& Setty BS. Activities and androgenic regulation of Kreb cycle enzymes in the epididymis and vas deferens of Rhesus monkey. Endocrine Research $199420275-$ 290.

12 Grootegoed JA \& DenBoer PJ. Energy metabolism of spermatids: a review. In Scientific Basis of Fertility Regulation Cellular and Molecular Events in Spermatogenesis, pp 193-216. Eds DW Hamilton \& GMH Waites. Cambridge: Cambridge University Press, 1990.

13 Grootegoed JA, Jansen R \& Van Der Molen HJ. The role of glucose, pyruvate and lactate in ATP production by rat spermatocytes and spermatids. Biochimica et Biophysica Acta 1984767 248-256.

14 Grootegoed JA, Jansen R \& Vander Molen HJ. Effect of glucose on ATP dephosphorylation in rat spermatids. Journal of Reproduction and Fertility 198677 99-107.

15 Nakamura M, Okinaga S \& Arai K. Studies of metabolism of round spermatids: glucose as unfavourable substrate. Biology of Reproduction $198635927-935$.

16 Nakamura M \& Hall PF. The mechanism by which body temperature inhibits protein biosynthesis in spermatids from rat testes. Journal of Biological Chemistry 1980255 2907-2913.

17 Jutte NHPM, Jansen R, Grootegoed JA, Rommerts FFG, Clausen OPF \& Vander Molen HJ. Regulation and survival of rat pachytene spermatocyte by lactate supply from Sertoli cells. Journal of Reproduction and Fertility 198265 431-438.
18 Grootegoed JA, Oonk RB, Toebosch AMW \& Jansen R. Extracellular factors that contribute to the development of spermatogenic cells. In Molecular and Cellular Endocrinology of the Testis, pp 215-225. Eds M Stefanini, M Conti, R Geremia \& E Ziparo. Amsterdam: Excerpta Medica, 1986.

19 Setchell BP. The secretion of fluid by the testes of rats, ram and goats with some observations on the effect of age, cryptorchidism and hypophysectomy. Journal of Reproduction and Fertility 197023 79-85.

20 Evan RW \& Setchell BP. The effect of rete testis fluid on the metabolism of testicular spermatozoa. Journal of Reproduction and Fertility 197852 15-19.

21 Free MJ. Carbohydrate metabolism in the testis. In The Testis, vol 2 , pp 125-192. Eds AD Johnson, WR Gomes \& NL Van Demark. New York: Academic Press, 1970.

22 Robinson R \& Fritz IB. Metabolism of glucose by Sertoli cells in culture. Biology of Reproduction 198124 1032-1041.

23 Grootegoed JA, Oonk RB, Jansen R \& Vander Molen HJ. Metabolism of radiolabelled energy-yielding substrates by rat Sertoli cells. Journal of Reproduction and Fertility 1986 b 77 109118.

24 Nakamura M, Okinaga S \& Arai K. Studies of metabolism of round spermatids: gGlucose as unfavourable substrate. Biology of Reproduction $198635927-935$.

25 Mita M, Price JM \& Hall PF. Stimulation by follicle-stimulating hormone for synthesis of lactate by Sertoli cells from rat testis. Endocrinology 1982110 1535-1541.

26 Mullaney BP, Rosselli M \& Skinner MK. Developmental regulation of Sertoli cell lactate production by hormones and the testicular paracrine factor, PModS. Molecular Cell Endocrinology 1994104 $67-73$.

27 Mann T \& Lutwak-Mann C. Enzymes as biochemical markers in differentiating germ cells. In Male Reproductive Function and Semen, pp 101-106. Berlin, Heidelberg, New York: SpringerVerlag, 1981.

Received 4 July 1997

Accepted 4 November 1997 